\title{
Investigation of the Effectiveness of Quercetin on Acrosome Integrity of Merino Ram Sperm
}

\author{
Ali Doğan Ömürr ${ }^{1,3,4, *}$, Oğuzhan Uluyol ${ }^{2}$ \\ ${ }^{1}$ Atatürk University Faculty of Veterinary Medicine, Department of Reproduction and Artificial Insemination, Erzurum, Turkey \\ ${ }^{2}$ Uluyol-Ak Veterinary Clinic, Inegol, Bursa, Turkey \\ ${ }^{3}$ Atatürk University Faculty of Veterinary Medicine, Department of Biochemistry, Erzurum, Turkey \\ ${ }^{4}$ Ataturk University, Faculty of Science, Department of Molecular Biology and Genetics, Erzurum, Turkey \\ *Corresponding author: Ali Doğan Ömür, Atatürk University Faculty of Veterinary Medicine, Department of Reproduction and Artificial \\ Insemination, Erzurum, Turkey
}

Received date: 20 February, 2022

Accepted date: 01 March, 2022 |

Published date: 03 March, 2022

Citation: Ömür AD, Uluyol O. (2022) Investigation of the Effectiveness of Quercetin on Acrosome Integrity of Merino Ram Sperm J Clin Vet Res 2(1): doi https://doi.org/10.54289/JCVR2200102

Copyright: (C) 2022 Ömür AD, et al. This is an open-access article distributed under the terms of the Creative Commons Attribution License, which permits unrestricted use, distribution, and reproduction in any medium, provided the original author and source are credited.

\begin{abstract}
To achieving high efficiency in sheep, ram sperm must have high fertilization ability. Quercetin, a potent antioxidant, has been shown to have a positive effect on semen in different species. This study aims to improve the efficiency of the Merino ram sperm using quercetin. The ejaculates collected from Merino rams were used for the dilution of the sperm (sperm density $\geq 3 \times 109$ spermatozoa $/ \mathrm{ml}$, motility $\geq 75 \%$ ). Tris diluent was used to dilute the semen. The ejaculates were divided into 4 equal volumes at $32{ }^{\circ} \mathrm{C}$. Three groups were formed by adding quercetin $(15,30,45 \mu \mathrm{g} / \mathrm{mL})$ at different doses. Antioxidant (quercetin) did not participate in the 4th group (the control group). Spermatozoa were diluted and frozen to approximately 4x108 spermatozoa per ml with Tris diluent. After thawing, the master mix was prepared with $60 \mu 1$ semen, $10 \mu 1$ FITC-PNA and $2.5 \mu \mathrm{PI}$ and allowed to incubate at $37^{\circ} \mathrm{C}$ for 20 minutes. The reaction was then terminated after treatment with $10 \mu \mathrm{L}$ Hancock solution. An amount of $2.5 \mu \mathrm{l}$ of the sample was taken and 200 sperm were counted at 400 magnifications on a fluorescent microscope. Sperm cells with a green color were evaluated as damaged acrosome, and no green colour was regarded as undamaged acrosome. In terms of the undamaged percentage of acrosomal integrity was assessed in the control group and quercetin groups $(15,30$, and $45 \mu \mathrm{g} / \mathrm{mL})$. Findings: $39.16 \pm 2.65 \mathrm{~b}$ in the $15 \mu \mathrm{g} / \mathrm{mL}$ group, $40.83 \pm 0.30 \mathrm{~b}$ in the $30 \mu / \mathrm{mL}$ group, $20.83 \pm 2.95 \mathrm{a}$ in the $45 \mu \mathrm{g} / \mathrm{mL}$ group and $54.83 \pm 3.38 \mathrm{c}$ in the control group. The percentage of the three groups formed with the quercetin substance added at different doses $(15,30,45 \mu \mathrm{g} / \mathrm{mL})$ were lower than the control group. Quercetin has been shown to toxicize acrosome integrity at these doses.
\end{abstract}

The study consisted of 6 replicates.

Keywords: Acrosome İntegrity; Quercetin; Ram; Semen.

\section{Introduction}

Sheep breeding has an important place in animal production, therefore in agricultural production and the economies of countries. Products such as meat, milk and dairy products, fleece and leather obtained from sheep meet the important needs of people. These animals can utilize feed sources that 
many livestock species cannot utilize. For these reasons, sheep breeding is carried out all over the world. While sheep breeding is so important, it is aimed to increase productivity in sheep breeding. In order to increase production in sheep breeding, it is necessary to get more yield from a unit animal. For this purpose, it is necessary to improve the breeding characteristics of sheep. It is obvious that a high-fertile offspring cannot be obtained from a female whose fertility is not good, samely, a good reproductive yield cannot be obtained from a male animal whose semen quality are not suitable. For these reasons, it is important that the fertilization ability of the ram sperm is high in the efficient continuation of sheep breeding. In order to increase the fertilization ability of ram semen, antioxidant substances are used especially to reduce the damaged sperm cells after freezing-thawing [1].

After freezing-thawing, the antioxidant capacity of semen decreases and the formation of reactive oxygen radicals increases, causing adverse effects on spermatological characteristics and fertility. Freeze-thawed semen is more sensitive to peroxidation than fresh semen. Recent studies point to the peroxidation of spermatozoa membrane lipids as the most important factor causing infertility during semen preservation. For this reason, antioxidant substances are added to semen extenders due to the thought that they may have positive effects on spermatological properties after freezing-thawing [2].

Antioxidant substances, which are present in high amounts in body fluids and reproductive tissues of mammals, when added to semen extender, reduce the peroxidation of fatty acids and phospholipids in the cell membranes caused by free radicals in the semen [3].

Quercetin is an antioxidant with flavonoid structure, consisting of 3 rings and 5 hydroxyl groups and is widely found in different plant materials such as fruits, vegetables, and grains [4-6].

Besides, quercetin is a powerful antioxidant with broad biological effects such as anticarcinogenic, antiasthmatic, antiviral, antiallergenic, antihypertensive, hepatoprotective, antidiabetic, anti-inflammatory, cardioprotective and antibacterial activities. It is found in vegetables and fruits such as apples, onions and red wine, grapefruit, black tea, raspberries, blueberries, cherries, broccoli, and it is a type of flavonoid that daily consumption of $25-30 \mathrm{mg}$ is sufficient for humans [6-9].

Because quercetin is a powerful antioxidant, it can improve sperm quality by reducing the damage caused by reactive oxygen species $[\mathbf{1 0 , 1 1}]$.

It is aimed to investigation of the effectiveness of quercetin on sperm acrosome integrity of merino ram sperm.

\section{Material And Method}

Prior to the project application, the approval of Atatürk University Animal Experiments Local Ethics Committee was obtained (No: 2016/145).

\section{Animal Material}

The study was carried out by obtaining ejaculates from 6 adult Merino rams aged 2-5 years with the help of an artificial vagina twice a week for 3 weeks. Those with suitable characteristics (sperm density $\geq 3 \times 10^{9}$ spermatozoa / ml; motility $\geq 80 \%$ ) among the ejaculates obtained were used in the study.

\section{Dilution and Evaluation of Sperma}

Tris extender (297.58 mM tris, $96.32 \mathrm{mM}$ citric acid, 82.66 $\mathrm{mM}$ fructose, $15 \%$ egg yolk, glycerol $5 \%$, gentamicin $0.1 \mathrm{ml}$ / 100ml: pH 6.8-7.0) was used for dilution of the semen. The ejaculates were divided into 6 equal volumes at $32{ }^{\circ} \mathrm{C}$ and diluted with Tris diluent containing quercetin $(15,30$, and $45 \mu \mathrm{g} / \mathrm{mL}$ ) and containing no antioxidant (control) to approximately $4 \times 10^{8}$ spermatozoa per $\mathrm{ml}$. After dilution, the semen samples were kept at room temperature for 10 minutes, then they were filled into $0.25 \mathrm{ml}$ straws and left to equilibrate at $+5{ }^{\circ} \mathrm{C}$ for approximately 3 hours. In the period following the equilibration, samples were frozen in liquid nitrogen vapor $\left(\sim-100{ }^{\circ} \mathrm{C}\right)$ for 10 minutes and stored in liquid nitrogen at $-196{ }^{\circ} \mathrm{C}$. The study consisted of 6 replications.

\section{Determination of Sperm Acrosome Integrity}

In the study, semen samples with and without antioxidants were evaluated in terms of acrosome integrity using fluorescent staining techniques.

Sperm acrosome status was assessed using fluorescein isothiocyanate conjugated to Arachis hypogea (peanut) (L7381 FITC-PNA, Invitrogen) and PI staining as described by Nagy et al. (2003). About $120 \mu$ g of FITC-PNA was added to $1 \mathrm{ml}$ of PBS (15630056, Invitrogen) to make staining 
solution, and then divided into equal aliquots $(100 \mu \mathrm{l})$ after filtering and stored at $-20{ }^{\circ} \mathrm{C}$. The thawed straw was (at 37 ${ }^{\circ} \mathrm{C}$ for 30 seconds) diluted 1: 3 with Tris stock solution without glycerol and egg yolk, and then $60 \mu \mathrm{l}$ of diluted semen were mixed with $10 \mu \mathrm{l}$ of FITC-PNA and $2.5 \mu \mathrm{l}$ of PI. The sample was gently mixed, incubated at $37^{\circ} \mathrm{C}$ in the dark for $20 \mathrm{~min}$, and then $10 \mu \mathrm{l}$ of Hancock solution were added to stop sperm movement. A wet mount was made using a $2.5 \mu \mathrm{l}$ drop of sample placed directly on a microscope slide and covered by a cover slip. At least 200 sperm cells were examined at $400 \times$ magnification under a fluorescence microscope (Leica DM 3000; excitation at 450-490 nm, emission at $520 \mathrm{~nm}$ ) to assess the sperm acrosome integrity.
Spermatozoa displaying bright green or patchy green fluorescence were considered as acrosome non-intact or damaged, whereas cells that did not stain green in the acrosome cap were regarded as acrosome intact.

\section{Statistical Analysis}

In the study, in order to compare four different groups with statistical analysis, analysis of variance and Post Hoc Tukey HSD test were used to compare more than two groups with significant differences between them. SPSS 15.0 for Windows Evaluation Version statistical analysis program was used. As a result, the difference at the $\mathrm{P}<0.001$ level was accepted as very significant.

\section{Results}

Table 1. Effect of quercetin on acrosome integrity ( \pm SEM)

\begin{tabular}{|c|c|}
\hline Groups & Rate of undamaged acrosomes (\%) \\
\hline Control & $54,83 \pm 3,38^{\mathrm{c}}$ \\
\hline Quercetin $15 \mu \mathrm{g} / \mathrm{mL}$ & $39,16 \pm 2,65^{\mathrm{b}}$ \\
\hline Quercetin $30 \mu \mathrm{g} / \mathrm{mL}$ & $40,83 \pm 0,30^{\mathrm{b}}$ \\
\hline Quercetin $45 \mu \mathrm{g} / \mathrm{mL}$ & $20,83 \pm 2,95^{\mathrm{a}}$ \\
\hline $\mathrm{P}$ & $*$ \\
\hline
\end{tabular}

$\mathrm{a}, \mathrm{b}, \mathrm{c}$ : Differences between means with different letters in the same column are significant $(*: \mathrm{p}<0.001)$.

The effect of quercetin at different doses on the acrosome integrity of ram semen is shown in Table 1. In the control group without quercetin, the percentage of intact acrosome integrity was found to be $54.83 \pm 3.38^{\mathrm{c}}$. When the effects of different doses of quercetin substances on acrosome integrity are examined.

The percentage of undamaged acrosomes was found to be $39.16 \pm 2.65^{\mathrm{b}}$ in the semen group that added $15 \mu \mathrm{g} / \mathrm{mL}$ quercetin. When this result is compared with the control group. It was determined that the ratio of undamaged acrosomes was lower than the control group and this difference was statistically significant. It was evaluated that the addition of $15 \mu \mathrm{g} / \mathrm{mL}$ quercetin had a negative effect on the acrosome integrity.

The percentage of acrosomes that were not damaged in the sperm group that added $30 \mu \mathrm{g} / \mathrm{mL}$ quercetin was found to be $40.83 \pm 0.30 \mathrm{~b}$. When this result is compared with the control group. It was determined that the ratio of undamaged acrosomes was lower than the control group and this difference was statistically significant. The difference between the group that added $30 \mu \mathrm{g} / \mathrm{mL}$ quercetin and the group that added $15 \mu \mathrm{g} / \mathrm{mL}$ quercetin was not significant but was similar.

The percentage of undamaged acrosomes in the semen group with $45 \mu \mathrm{g} / \mathrm{mL}$ quercetin was found to be $20.83 \pm 2.95^{\mathrm{a}}$. When this result is compared with the control group. It was determined that the rate of undamaged acrosomes was much lower than the control group. The difference between the control group and the other two $(15 \mu \mathrm{g} / \mathrm{mL}$ quercetin, $30 \mu \mathrm{g} / \mathrm{mL}$ quercetin) groups was statistically significant. It 
was determined that the addition of $45 \mu \mathrm{g} / \mathrm{mL}$ quercetin had a toxic effect on the acrosome integrity. Below are the microscopic images of the undamaged acrosome (Red
Colored Sperm Cell) integrity of the control group and the sperm groups with different doses of quercetin.

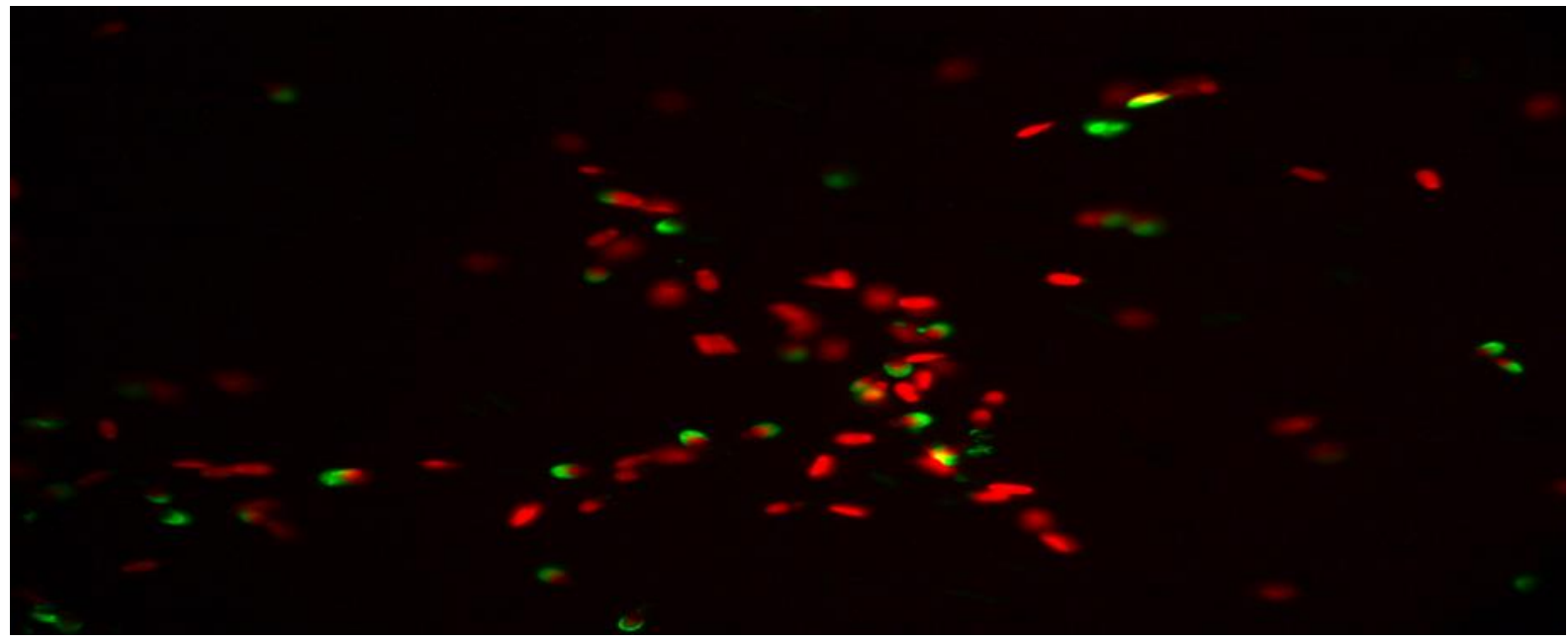

Figure 1.: Microscopic image of undamaged acrosome integrity in the control group.

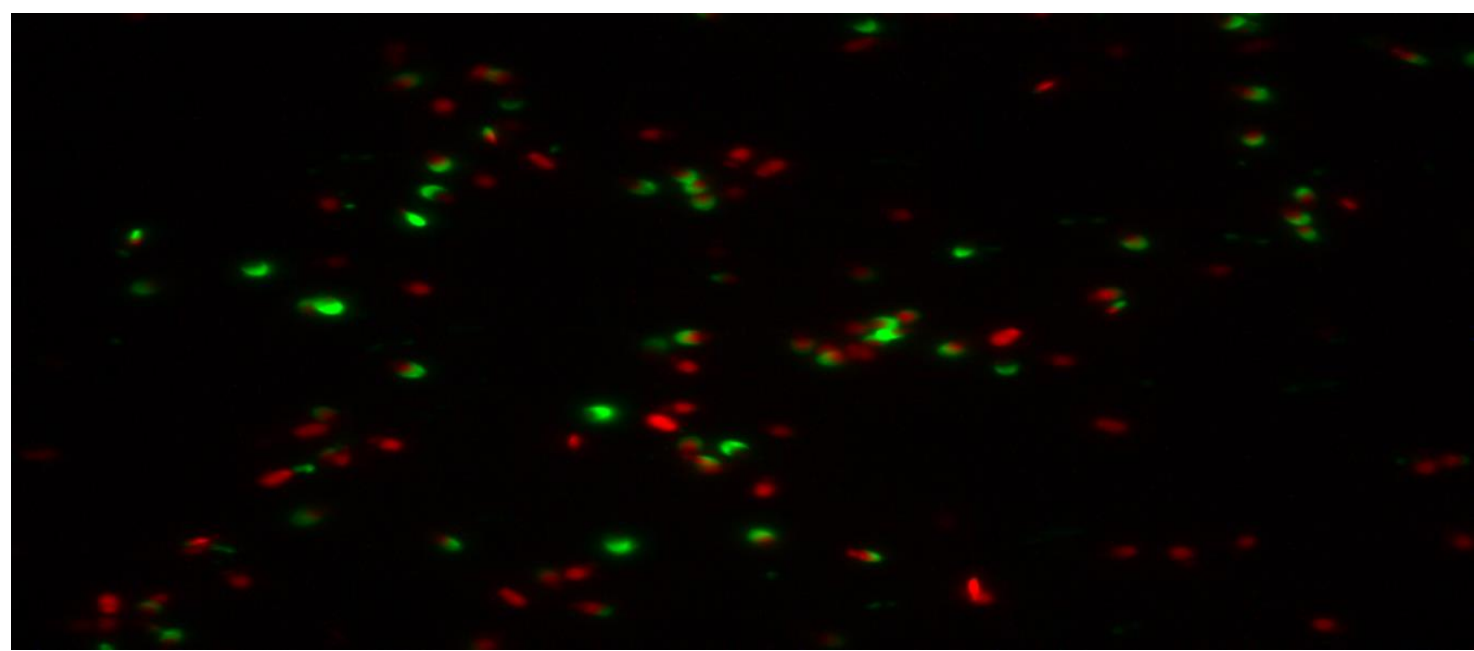

Figure 2.: Microscopic image of undamaged acrosome integrity in the $15 \mu \mathrm{g} / \mathrm{mL}$ quercetin group.

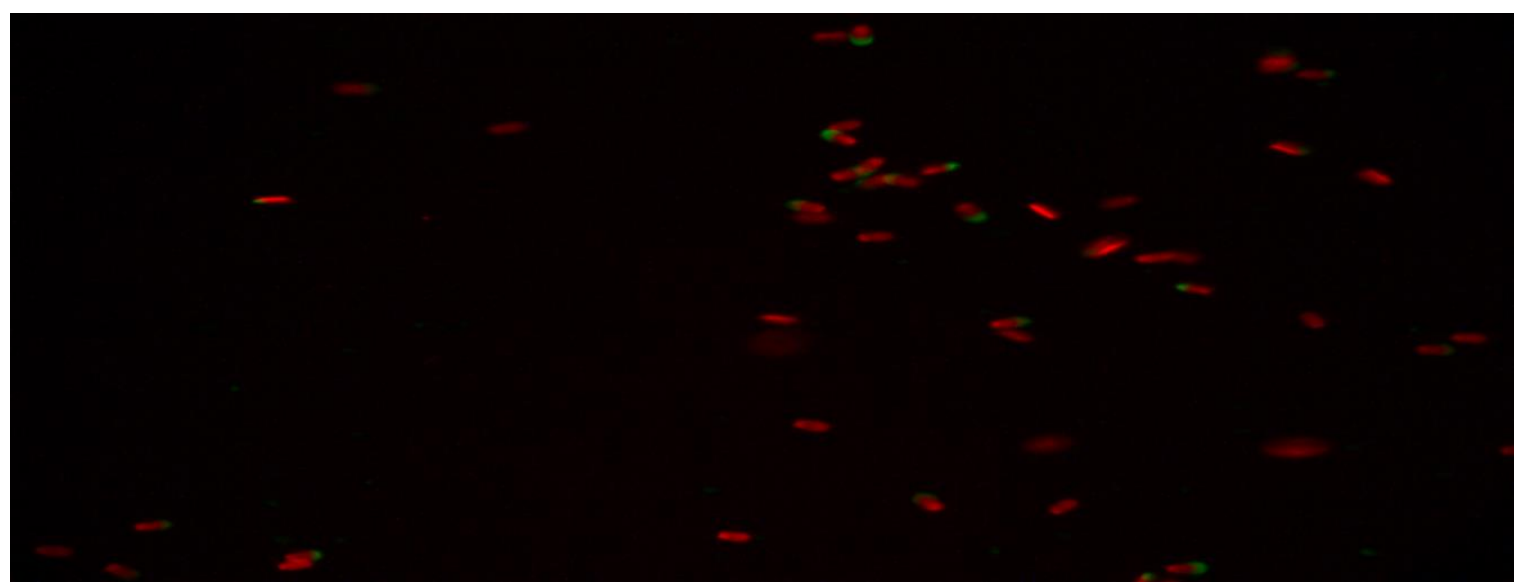

Figure 3.: Microscopic image of undamaged acrosome integrity in the $30 \mu \mathrm{g} / \mathrm{mL}$ quercetin group. 


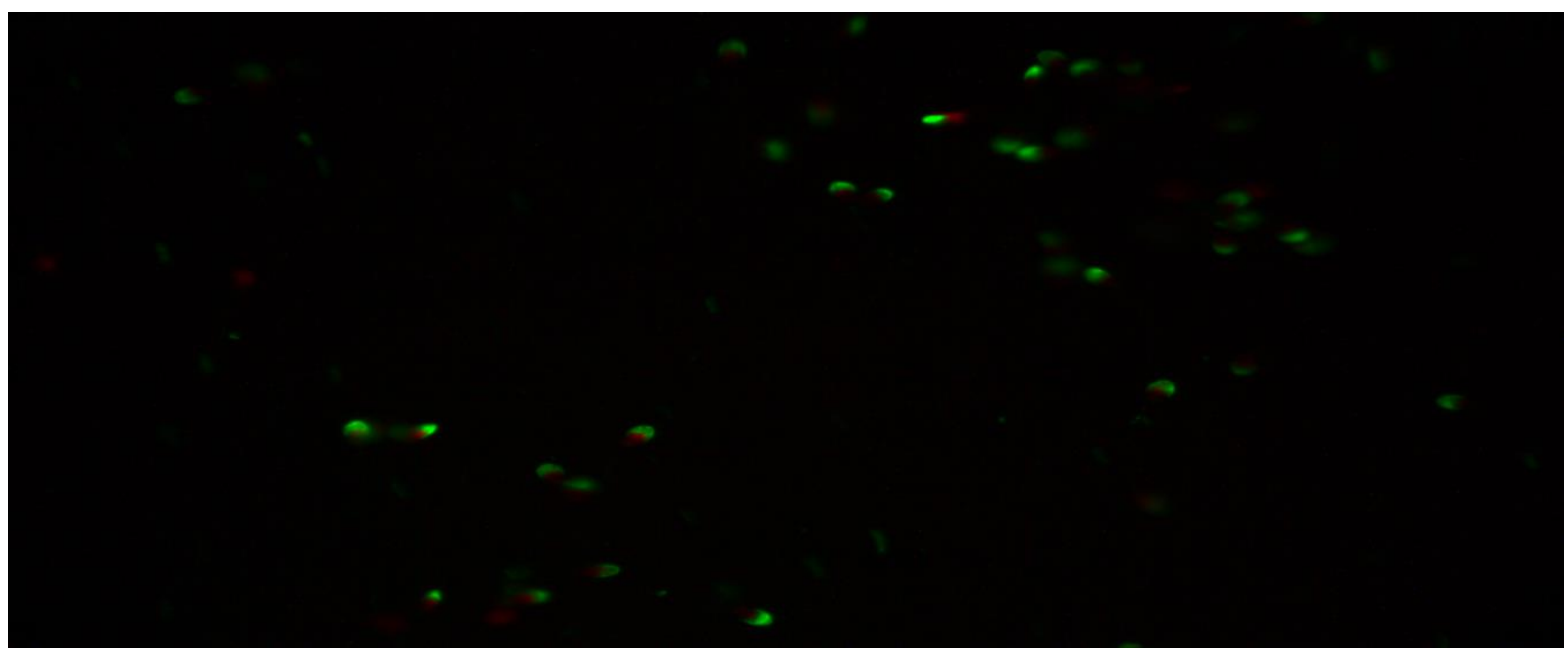

Figure 4.: Microscopic image of undamaged acrosome integrity in the $45 \mu \mathrm{g} / \mathrm{mL}$ quercetin group.

\section{Discussion}

Many in vivo and in vitro studies have been conducted on the antioxidant potential of quercetin. These studies showed that the antioxidant effect of quercetin protects the brain, heart, testicles, and other tissues against ischemia-reperfusion damage, toxic compounds and other factors caused by oxidative stress [9]. Quercetin is recognized as a powerful antioxidant due to its ability to retain Reactive oxygen species (ROS) and Reactive nitrogen species (RNS). It has also been stated that it directly destroys lipid peroxides [12] and indirectly increases the efficiency of enzymatic antioxidants and increases the production of nonenzymatic antioxidants [13].

Quercetin $(10 \mu \mathrm{mol} / \mathrm{L})$ application to semen obtained from leukocytospermic patients was seen a positive effect on sperm motility and acrosome reaction. Besides, the level of $\mathrm{H}_{2} \mathrm{O}_{2}$ was significantly decreased in the supernatant of leukocytospermic patients after Quercetin treatment [11].

On the other hand, $15 \mathrm{mM}$ quercetin loaded nanostructured lipid carrier improved rooster sperm quality parameters [14]. It is well known; an intact functional sperm acrosome is an essential prerequisite for oocyte fertilization [15]. Sperm with damaged acrosomes or undergoing an early acrosome reaction after freezing thawing lose their ability to attach to the zona pellucida and are no longer able to fertilize. In other words, acrosome-reacting sperm have a short lifespan [16] and eventually an increase in the proportion of such sperm will adversely affect the fertilization capacity of semen doses [17].

When it was interpreted the findings obtained from our research, it can be understanding the exceed dosage of quercetin may be harmful effect on sperm acrosome integrity. Conflict of interest: The authors declared no potential conflicts of interest with respect to the research, authorship, and/or publication of this article.

Funding: The authors received no financial support for the research, authorship, and/or publication of this article.

ORCID ID: Ali Doğan ÖMÜR https://orcidorg/0000-00022976-4368

\section{References:}

1. Akçapınar H. (1994) Sheep Breeding. Medisan Publishing. No: 8.

2. Kulaksız R, Daşkın A. (2009) In vitro and in vivo evaluation of Saanen goat semen frozen with different antioxidants. Ankara Univ Vet Fak Derg. 56(3): 201205.

3. Bucak MN, Sariozkan S, Tuncer PB, Sakin F, Atessahin A, et al. (2010) The effect of antioxidants on post-thawed Angora goat (Capra hircus ancryrensis) sperm parameters, lipid peroxidation and antioxidant activities. Small Rumin. Res. 89(1): 24-30.

4. Kocabaş N. (2008) Protective Effect of Quercetin on Homocysteine Induced Oxidative Stress. Institute of Health Sciences, Department of Biochemistry, Master, Afyon: Kocatepe University. 
5. Khaki A, Nouri M, Fathiazad F, Ahmadi-Ashtiani H, Rastgar H, et al. (2009) Protective effects of quercetin on spermatogenesis in streptozotocin-induced diabetic rat. Journal of Medicinal Plants. 8(5): 57-64.

6. Nabavi SF, Russo GL, Daglia M, Nabavi SM. (2015) Role of quercetin as an alternative for obesity treatment: you are what you eat. Food Chemistry. 179: 305-310.

7. Y1lmaz İ. (2010) Some foods containing antioxidants and oxidative stress. Turgut Özal Medical Center Journal. 17(2): 143-154.

8. Gibellini L, Pinti M, Nasi M, Montagna J, De Biasi S, et al. (2011) Quercetin and cancer chemoprevention. Evidence-based Complementary and Alternative Medicine. (3): 591356.

9. Kelly GS. (2011) Quercetin. Altern. Med. Rev. 16(2): 172-194.

10. Avdatek F, Yeni D, İnanç M.E, Çil B, Tuncer BP, et al. (2018) Supplementation of quercetin for advanced DNA integrity in bull semen cryopreservation. Andrologia. 50(4): $1-7$.

11. Diao R, Gan H, Tian F, Cai X, Zhen W, et al. (2019) In vitro antioxidation effect of Quercetin on sperm function from the infertile patients with leukocytospermia. American Journal of Reproductive Immunology. 82(3): e13155.

12. Baghel SS, Shrivastava N, Baghel RS, Agrawal P, Rajput S. (2012) A review of quercetin: antioxidant and anticancer properties. World J Pharm Pharmaceutical Sci. 1(1): 146-160.

13. Nabavi SF, Nabavi SM, Mirzaei M, Moghaddam AH. (2012) Protective effect of quercetin against sodium fluoride induced oxidative stress in rat's heart. Food \& function. 3(4): 437-441.

14. Najafi A, Kia HD, Mehdipour M, Hamishehkar H, Álvarez-Rodríguez, et al. (2020) Effect of quercetin loaded liposomes or nanostructured lipid carrier (NLC) on post-thawed sperm quality and fertility of rooster sperm. Theriogenology. 152: 122-128.

15. Thundathil J, Gil J, Januskauskas A, Larsson B, Soderquist L, et al. (1999) Relationship between the proportion of capacitated spermatozoa present in frozenthawed bull semen and fertility with artificial insemination. Int J Androl. 22(6): 366-373.

16. Hino T, Muro Y, Tamura-Nakano M, Okabe M, Tateno $\mathrm{H}$, et al. (2016) The behavior and acrosomal status of mouse spermatozoa in vitro, and within the oviduct during fertilization after natural mating. Biol Reprod. 95(3): 50 .

17. Michailov Y, Lunenfeld E, Kapilushnik J, Friedler S, Meese E, et al. (2019) Acute myeloid leukemia affects mouse sperm parameters, spontaneous acrosome reaction, and fertility capacity. Int J Mol Sci. 8 20(1): 219. 